\title{
$\widehat{A}$ Madridge \\ madridge Journal of Dermatology \& Research \\ Interconnecting Scientific World
}

Case Study

Open Access

\section{Utility of Belgium Outcome of Burn Injury Score (BOBI score) in Predicting Mortality in Burn patients- Case Report}

\author{
Ravi Kumar Chittoria ${ }^{1 \star}$, Abhishek G Nair ${ }^{2}$, Nishad Kerakada ${ }^{3}$, Dandugula Pavan Kumar ${ }^{2}$ and Aditya Yadav ${ }^{2}$ \\ ${ }^{\prime}$ Professor, Department of Plastic Surgery \& Telemedicine, Jawaharlal Institute of Postgraduate Medical Education and Research \\ (JIPMER), Pondicherry, India
}

2Junior Resident, Department of General Surgery, JIPMER, Pondicherry, India

${ }^{3}$ Senior Resident, Department of Plastic Surgery, JIPMER, Pondicherry, India

\section{Article Info}

\section{*Corresponding author: \\ Ravi Kumar Chittoria \\ Professor \& Registrar (Academic) \\ Department of Plastic Surgery \& \\ Telemedicine \\ JIPMER, Pondicherry \\ India \\ Email: drchittoria@yahoo.com}

Received: November 22, 2021

Accepted: December 02, 2021

Published: December 08, 2021

Citation: Chittoria RK, Nair AG, Kerakada N, Kumar DP, Yadav A. Utility of Belgium Outcome of Burn Injury Score (BOBI score) in Predicting Mortality in Burn patientsCase Report. Madridge J Dermatol Res. 2021; 5(1): 110-112.

doi: $10.18689 / \mathrm{mjdr}-1000129$

Copyright: (c) 2021 The Author(s). This work is licensed under a Creative Commons Attribution 4.0 International License, which permits unrestricted use, distribution, and reproduction in any medium, provided the original work is properly cited.

Published by Madridge Publishers

\begin{abstract}
The prediction of the outcome of patients presenting with severe burns is crucial in guiding clinical judgments. There are multiple models for predicting burn mortality that have been developed over many years. Advancements in burn management over the years have significantly decreased burn mortality. However, higher death rates are still a glaring issue in developing countries where these advancements are yet to be implemented. And in such countries the scoring system needs to be implemented routinely for every patient to find out the mortality and thus to improve the infrastructure and to train the manpower accordingly. There are various scoring systems that are formularized in predicting mortality in burns. In this article we would like to describe our pilot study in using Belgium outcome of burn injury scoring system in predicting mortality in burns patients.
\end{abstract}

Keywords: Belgium Outcome of Burn Injury Score (BOBI), Burn, Mortality

\section{Introduction}

Burns injury is one of the important factors contributing to mortality in a developing country like India [1]. Predicting the mortality in burns patient on presentation to hospital in low resource nations like India helps in determining the prognosis of the patient and effective handling of resources. Prognostic scoring systems for burn patients help in assessing the severity of the condition and its likely course, thereby ultimately allowing stratification of risk numerically and scientifically which can be statistically analysed. There is no scoring system that accurately predicts mortality due to burns or helps in determining the course, treatment options and evaluating new or innovative interventions uniformly. Revised Bauxscore [2], Abbreviated Burn Scoring Index (ABSI) [3], Ryan et al [4], Belgium Outcome of Burn Injury (BOBI) [5], Smith et al [6], McGwin et al [7] are some of the scoring systems available which can be used to predict the mortality in burn patients. There is a need for the most appropriate scoring system which can be used for bedside risk assessment, and counselling in burns patients. So, there is a need to test all available scoring systems and to choose the one which helps to predict the outcome.

In this article we share the details of a pilot study on Belgium Outcome of Burn Injury scoring system. 


\section{Materials and Methods}

The study was conducted in a Burn unit under Department of Plastic surgery of a tertiary care centre in South India during October 2021. Department Ethical Committee approval and patient consent were obtained before the study. The objective of the study was to conduct a pilot study to test the $\mathrm{BOBI}$ scoring system on burn patients admitted in a burn centre and the study included two patients admitted on the same day with Burn injury and to follow up the patients and to find out if the $\mathrm{BOBI}$ can predict the outcome of the patient precisely.

\section{Case report 1}

The first patient was a 32-year-old female with no known comorbidities who presented to emergency with thermal flame burns over face, neck, both upper limbs and with singed of nasal hairs on the same day of burn. In emergency, patient was conscious, Pulse Rate 122/min, Blood Pressure 90/70 $\mathrm{mmHg}$, Respiratory Rate22/min, SPO295\% on room air. Rule of Nine chart was used to calculate the TBSA involved and on detailed assessment, about $25 \%$ burns were superficial $2^{\text {nd }}$ degree and $10 \%$ burns were deep $2^{\text {nd }}$ degree. On presentation $\mathrm{BOBI}$ score of 4 (age- 0 , inhalational injury-3, \%TBSA-1) with a predicted survival of $80 \%$. Patient was resuscitated with IV fluids as per Parkland formula, she was given Nebulization using bronchodilators, $\mathrm{N}$-acetyl cystine and Heparin with normal saline. She was initially given heterografting with dry bovine collagen, then she underwent tangential excision, Integra application on day 2 of admission. Patient developed respiratory distress and was intubated on day 4 . The patient expired on day5 of burns injury.

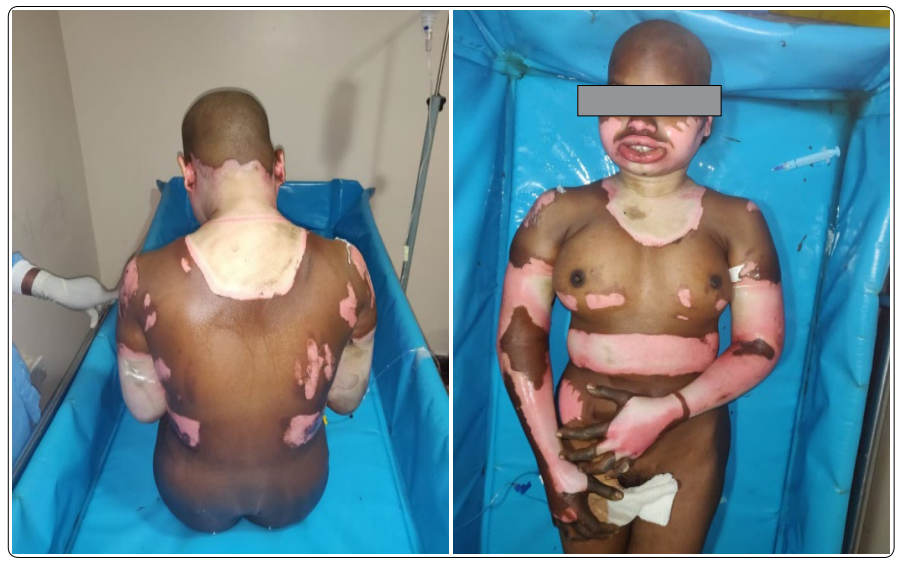

Figure 1. 32 year old female with 35\% TBSA burns and Inhalational Burn

\section{Case report 2}

Our second patient was a 4-year-oldmale child with no antenatal/perinatal complications, or any congenital anomalies presented with scald burns over back, buttock, genital region on the same day of burn injury. In emergency, child was alert, Pulse Rate 132/min, Blood Pressure $80 / 60 \mathrm{mmHg}$, SPO298\% in room air. Total body surface area was calculated using Lund and Browder chart and on detailed assessment, $30 \%$ superficial $2^{\text {nd }}$ degree and $10 \%$ deep $2^{\text {nd }}$ degree scald burns. On presentation BOBI score of 2(age- 0 , inhalational injury-0, \%TBSA-2) with a survival of $95 \%$. He was resuscitated with IV fluids as per Parkland formula and maintenance fluids according to body weight. Wound management was done by heterografting with collagen, Prophylactic antibiotics were started. Patient developed enterococcus faecalis infection and was intubated on day 4 and expired on day 6 of burns injury.

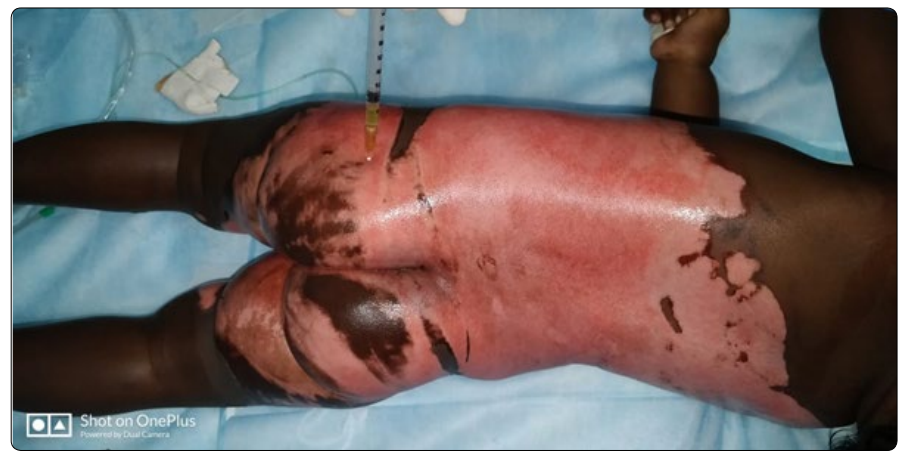

Figure 2. 4year old female with $40 \%$ TBSA Burns

\section{Discussion}

The World Health Organization (WHO) reported 1,80,000 deaths annually due to burn injury majority of which are contributed by low and middle-income countries where the resources are limited [8]. Even though advancements in burn injury management have significantly reduced the burn mortality, due to limited resources burn mortality is still high in developing countries [9] [Table 1].Every year in India, around $10,00,000$ people sustain moderate to severe burns [8]. In developing nations like India, the burn intensive care unit beds are limited owing to the shortage of trained health professionals and the high cost needed for maintenance. In present circumstances of limited bed availability, the need for burn scoring systems and prognostic scores are crucial in triaging burnt patients in accordance with their severity, for guiding the treatment, resource management and for counselling family members.

There are many predictors of mortality and many scoring systems available but none of them precisely predict the actual outcome in every situation. Most of the mortality predicting scores have been formulated in the developed countries and applied in their respective populations. Therefore, most of these prediction models fail to predict mortality in developing or underdeveloped nations precisely may be due to variations in the study population, standard of care or available resources.

The first prognostic factors found to be effective in predicting the mortality in patients burns was the Total surface area (TBSA) and age, which was first proposed by Weidenfeld, who in 1902 correlated TBSA and age with the mortality. The effectiveness of these two parameters was affirmed later 1949 by Bull and Squire in 1949 and later by Baux in 1963 as Baux score [10]. Abbreviated Burn Scoring Index (ABSI), Ryan et al, Belgium Outcome of Burn Injury $(\mathrm{BOBI})$, Smith et al, McGwin et al, are some of the scoring systems available which can be used to predict the mortality in burn patients. 
In the present study, we have applied Belgium Outcome of Burn Injury (BOBI) score to predict mortality. The BOBI score uses values of age, TBSA and presence of inhalational injury. The maximum score is 10 which give a $99 \%$ risk of mortality [5]. Incorporation of the well-known significant independent risk factors like Age, Total body surface area involved, and inhalational injury were found to have performed well in predicting burn mortality in various populations. BOBI score was chosen as it is a simpler scale to calculate bedside with high specificity when compared to other mortality predictor scales. Our patients had BOBI scores of 4 and 2 with a percent of survivability of $80 \%$ and $95 \%$ respectively. But both the patients expired which shows a higher risk of mortality.

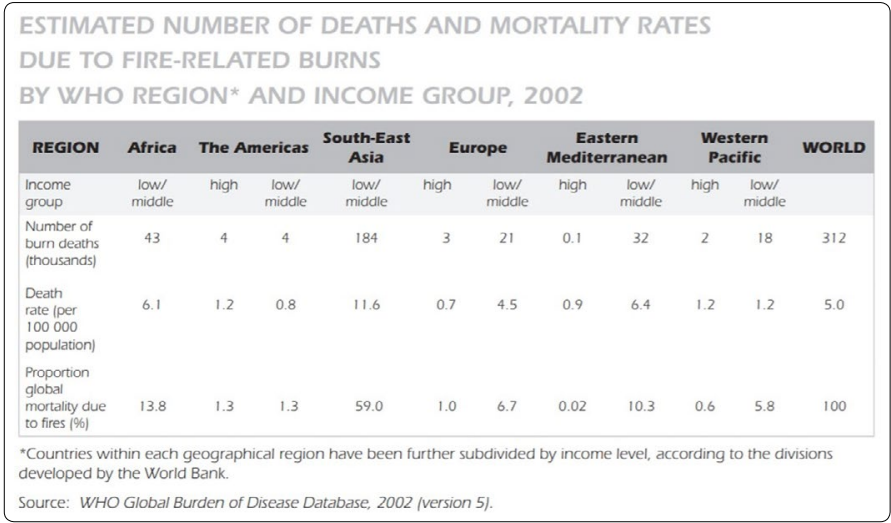

Table 1. WHO Global Burden of Disease Database 2002

\begin{tabular}{|c|c|c|c|c|}
\hline \multirow{2}{*}{\begin{tabular}{|l|} 
\\
BOBI
\end{tabular}} & \multicolumn{2}{|c|}{ AGE IN YEARS } & \multirow{2}{*}{\begin{tabular}{|l|} 
SCORE \\
0
\end{tabular}} & \multirow{2}{*}{\begin{tabular}{|l}
$\begin{array}{l}\text { MORTALITY } \\
\%\end{array}$ \\
0.1 \\
\end{tabular}} \\
\hline & $<50$ & 0 & & \\
\hline & $50-64$ & 1 & 1 & 1.5 \\
\hline & 65-79 & 2 & 2 & 5 \\
\hline & $>80$ & 3 & 3 & 10 \\
\hline & BURN & $\%$ & 4 & 20 \\
\hline & $<20$ & 0 & 5 & 30 \\
\hline & $20-39$ & 1 & 6 & 50 \\
\hline & $40-59$ & 2 & 8 & 75 \\
\hline & $60-79$ & 3 & 8 & 85 \\
\hline & $80-100$ & 4 & 9 & 95 \\
\hline & INHAL & NAL INJURY & 10 & 100 \\
\hline & YES & 3 & \multirow{2}{*}{\multicolumn{2}{|c|}{ TBSA: TOTAL BODY SURFACE AREA }} \\
\hline & NO & 9 & & \\
\hline
\end{tabular}

Table 2. Belgium Outcome of Burn Injury (BOBI)

\section{Limitations of the Study}

It is a case report from a single centre. With only very limited number of cases. A multicentre, Randomized control study is required to validate the efficacy in $B O B I$ score in predicting mortality in burn patients.

\section{Conclusion}

The study shows that BOBI can be used as a mortality predictor of burn patient and help in triaging the patient for the best use of resources available in developing countries like India. But the outcome of the patient cannot be precisely predicted by using the BOBI score alone. The scoring system requires standardisation for population and resource variability.

\section{References}

1. Agarwal $P$, Adalti $S$, Agrawal V, Sharma D. A simple mortality prognostic scoring system for burns. Indian J Burns. 2017; 25: 26-32.

2. Osler T, Glance LG, Hosmer DW. Simplified estimates of the probability of death after burn injuries: extending and updating the baux score. $J$ Trauma. 2010; 68(3): 690-697. doi: 10.1097/TA.0b013e3181c453b3

3. Tobiasen J, Hiebert JH, Edlich RF. Prediction of burn mortality. Surg Gynecol Obstet. 1982; 154(5): 711-714.

4. Ryan CM, Schoenfeld DA, Thorpe WP, Sheridan RL, Cassem EH, Tompkins RG. Objective estimates of the probability of death from burn injuries. $N$ Engl J Med. 1998; 338(6): 362-366. doi: 10.1056/NEJM199802053380604

5. Belgian Outcome in Burn Injury Study Group. Development and validation of a model for prediction of mortality in patients with acute burn injury. Br J Surg. 2009; 96(1): 111-117. doi: 10.1002/bjs.6329

6. Smith DL, Cairns BA, Ramadan F, Dalston JS, Fakhry SM, Rutledge R, et al. Effect of inhalation injury, burn size, and Age on mortality: a study of 1447 consecutive burn patients. J Trauma. 1994; 37(4): 655-659. doi: 10.1097/00005373-199410000-00021

7. McGwin G Jr, George RL, Cross JM, Rue LW. Improving the ability to predict mortality among burn patients. Burns. 2008; 34(3): 320. doi: 10.1016/j.burns.2007.06.003

8. World Health Organization : https://www.who.int/news-room/factsheets/detail/burns

9. Noor D.M., Wicaksana A., Fauzi A.R., et al. Comparison between revised Baux score and abbreviated burn severity index as a predictor of mortality in burnpatients at a tertiary care center in Yogyakarta, Indonesia. Eur J PlastSurg. 2020; 43: 53-58. doi: 10.1007/s00238-01901578-y

10. Bull JP, Squire JR. A study of mortality in a burns unit: Standards for the evaluation of alternative methods of treatment. Ann Surg. 1949; 130: 160-173. 